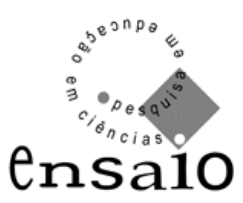

\title{
O QUE É E QUEM FAZ CIÊNCIA? \\ IMAGENS SOBRE A ATIVIDADE CIENTÍFICA DIVULGADAS EM FILMES DE ANIMAÇÃO INFANTIL
}

\author{
WHAT IS AND WHO DOES SCIENCE? \\ IMAGES ABOUT THE SCIENTIFIC ACTIVITY IN \\ ANIMATION FILMS FOR CHILDREN
}

\author{
Aline Luiza Tomazi* \\ Aline Julyê Pereira** \\ Cristiane Müller Schüler \\ Karin Piske \\ Daniela Tomio
}

\begin{abstract}
Resumo
Caracterizar as imagens de ciência e de cientista veiculadas em filmes de animação infantil - a fim de contribuir na discussão de alternativas didáticas para educação científica de crianças - é o objetivo desta pesquisa. Para tal, foram selecionados e analisados filmes desse gênero que contivessem mencionadas, em sua sinopse, as palavras ciência, cientista, laboratório, experimento, pesquisa, pesquisadores, investigação/lógica científica, invenção e inventor. Concluiu-se que os filmes trazem estereótipos sobre a ciência e que podem servir como alternativa didática desde que tenham como suporte uma discussão crítica sobre as concepções transmitidas. Sistematizou-se, também, um roteiro de observação com critérios que subsidiem o professor na análise do conteúdo dos filmes de animação infantil em relação às imagens da atividade científica que apresentam.
\end{abstract}

Palavras-chave: Ciência. Cientista. Filme de animação infantil.

\footnotetext{
Abstract

The aim of this research is characterize the images of science and scientist in movies of animation for younger audiences to contribute in the discussion of alternatives for scientific education of children. For this reason were selected and analyzed movies of

* Professora de Ciências na Rede Estadual de Ensino de Santa Catarina. Graduada em Ciências Biológicas. Universidade Regional de Blumenau (FURB), Blumenau, SC. aline_luiza_05@hotmail.com

** Graduada em Ciências Biológicas. Universidade Regional de Blumenau, Blumenau, SC. lynokaa@hotmail.com

*** Graduada em Ciências Biológicas. Universidade Regional de Blumenau, Blumenau, SC. cris_hz@yahoo.com.br

**** Graduada em Ciências Biológicas. Universidade Regional de Blumenau, Blumenau, SC. karinbio@hotmail.com

***** Professora no Curso de Ciências Biológicas na Universidade Regional de Blumenau. Doutoranda do Programa de Educação Científica e Tecnológica na Universidade Federal de Santa Catarina. danitomio@terra.com.br
} 


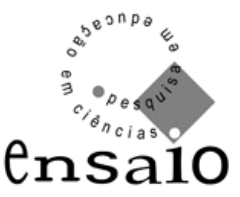

this genre, which had mentioned in its summary the words science, scientist, laboratory, experiment, research, researchers and/or research and scientific logic, invention and inventor. It was concluded that, the films bring stereotypes about science and they can serve as an alternative teaching since that they are supported by a critical discussion about the ideas expressed in them. It was also systematized a guide of observation with some criteria that subsidize the teacher in the analysis of the content of animation movies for younger audiences in relation to the images of scientific activity that they show.

Keywords: Science. Scientist. Movie of animation for younger audience.

\section{INTRODUÇÃO}

A mídia cinematográfica infantil veicula que imagens de ciência e cientista por meio de suas personagens? Filmes de animação infantil podem servir de instrumento para a educação científica? Com quais critérios os professores podem selecionar filmes de animação infantil com o objetivo de trabalhar questões relacionadas ao ensino da ciência na escola?

Questões como essas motivaram e justificaram uma pesquisa com o objetivo principal de caracterizar as imagens de ciência e do/a profissional cientista veiculadas em filmes de animação infantil, a fim de contribuir para o debate dessa alternativa didática para educação científica de crianças. Para isso, inicialmente se faz necessária a reflexão sobre duas grandes perguntas: “o que é ciência?” e "por que as crianças, que frequentam as escolas, precisam aprender ciência?”

Respostas para essas questões merecem importância, uma vez que as imagens que os professores possuem sobre a natureza da ciência e da atividade científica são transmitidas aos seus alunos nas escolhas didáticas que fazem. Conforme Cachapuz et al. (2005), estudos mostram que o ensino transmite visões de ciência, de tecnologia e do cientista muito distantes da forma como se constroem e se transformam os conhecimentos científicos e tecnológicos. Exemplos dessas visões podem ser observados quando se apresenta a ciência e a tecnologia aos alunos a partir de: a) uma concepção descontextualizada e socialmente neutra, esquecendo de problematizar os impactos nos meios naturais - sociais - culturais ou os interesses sócioeconômicos em seus desenvolvimentos; b) de uma visão de cientista/pesquisador individualista e elitista como se o conhecimento científico e tecnológico fosse obra de um "gênio", 


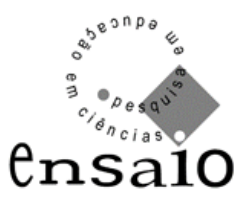

ignorando o trabalho de equipe e reforçando o papel de pessoas especialmente dotadas intelectualmente; c) uma concepção empírico-indutivista-teórica, que defende o papel da observação e da experimentação neutra e desconsidera o papel das teorias que orientam todo o processo; d) a percepção acumulativa e de "evolução" linear do conhecimento científico, reforçada pela transmissão aproblemática e a-histórica das informações do livro didático; e) a visão de um método científico único, que torna os resultados das pesquisas científicas e tecnológicas infalíveis e como certezas absolutas.

Ao contrário disso, é preciso na escola incentivar as crianças a refletirem a ciência como um conhecimento que auxilia a explicar o mundo e, ao mesmo tempo, como uma forma de produção coletiva, que está sintonizada com a cultura e as ideias do ser humano no seu contexto histórico-social. Por isso a relevância de se abordar o conhecimento científico considerando e problematizando as suas relações com a "história da sua produção”, a “tecnologia”, a “sociedade” e a “cultura” e isso implica aos professores:

[...] ir mais além da habitual transmissão de conhecimentos científicos, de incluir uma aproximação à natureza da ciência e à prática científica e, sobretudo, de enfatizar as relações ciência-tecnologia-sociedade-ambiente, de modo a favorecer a participação dos cidadãos na tomada fundamentada de decisões. (AIKENHEAD, 1985 apud CACHAPUZ et al., 2005, p.23).

Nessa perspectiva, pode-se refletir sobre outra pergunta, "por que aprender ciências na escola?” Para Delizoicov, Angotti e Pernambuco (2002), os resultados decorrentes da atividade científica ainda são pouco acessíveis à maioria das pessoas escolarizadas e, por isso, passíveis de uso e compreensão acríticos e ingênuos, evocando a necessidade de um ensino que possibilite os estudantes incorporarem no seu universo a ciência como cultura.

Para Tomio (2002), as crianças aprendem Ciências na escola, dentre outras justificativas, para: elaborarem conhecimentos científicos (saber) que lhes contribuam para problematizarem e/ou explicarem os fenômenos que acontecem nas realidades; formarem habilidades científicas (fazer) para acessarem informações e organizá-las criativamente, criticamente e de forma atuante na solução de problemas e praticarem novas atitudes (ser e conviver) para consigo, com os outros grupos sociais, com as 


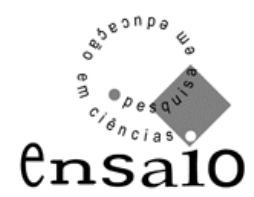

outras espécies e o meio - natural, social, cultural - contribuindo para uma vida ética, saudável e sustentável.

Com base nessa reflexão, pergunta-se "por que os filmes de animação infantil podem ser uma alternativa didática para educação científica de crianças?”

Nos dias atuais, a ciência cada vez mais se faz presente na sociedade e, como afirmam Oliveira (2006) e Silva et al. (2006), suas representações se manifestam em diversas expressões culturais. Essas demonstrações devem-se muito à mídia, a qual tem atuado sob diferentes perspectivas na divulgação científica, fazendo com que a concepção de ciência deixasse de ser restrita ao ambiente escolar e se manifestasse em todos os locais sociais.

No entanto, ainda é na escola que as crianças podem ter uma relação mais concreta com o estudo da ciência, através da ação mediada exercida pelo professor. Assim, a ciência precisa ser mostrada ao aluno como uma atividade humana e o cientista como um trabalhador, ambos de um mundo real, concreto e historicamente determinado, devendo os conceitos e os procedimentos científicos contribuir para ele questionar o que vê e ouve, interpretar os fenômenos naturais e compreender a intervenção da sociedade na natureza. (BRASIL, 1998).

Sobre as imagens que os estudantes possuem da ciência e do/a cientista, pesquisadores como Kosminsky e Giordan (2002); Reis e Galvão (2006); Silva et al. (2005); Zompero, Garcia e Arruda (2005), dentre outros, trazem em comum, nas conclusões de seus estudos, que os alunos têm uma imagem estereotipada do cientista, imaginando-o muito inteligente, velho, louco, cabeludo e despenteado, cujo principal local de trabalho é o laboratório, estando a ciência relacionada a descobertas e como uma verdade única.

Pesquisas têm apontado, ainda, que a visão de ciência de crianças e adolescentes sofre uma influência determinante dos veículos de comunicação e mesmo da divulgação científica, tais como desenhos animados, filmes, séries de televisão, livros, telejornais ou revistas (KOSMINSKY; GIORDAN, 2002; OLIVEIRA, 2006; REIS; RODRIGUES; SANTOS, 2006; SIQUEIRA, 2006). Assim, os meios de comunicação social parecem assumir um papel de destaque na veiculação de diversas imagens estereotipadas sobre as características pessoais ou a atividade profissional do cientista, como destaca Francisco (2006), com sua pesquisa, ao alertar 


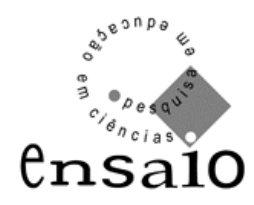

que a mídia está presente e acompanha o indivíduo desde a tenra idade e que os filmes animados exercem forte influência na maneira do pensar infantil.

Ao relacionar o uso de animação cinematográfica para veicular uma concepção de ciência, Siqueira (2006, p.145) afirma que:

\begin{abstract}
As animações podem ser uma forma de estimular as crianças a se interessarem por temas variados, inclusive a ciência, de forma provocativa, interessante e criativa. Podem apresentar os desafios éticos da profissão de cientista, podem cumprir a tarefa de reaproximar a ciência da vida - o que a ciência moderna tentou distanciar.
\end{abstract}

Nunes (2006) também faz notar que os filmes de animação deveriam apresentar os desafios da profissão de cientista, reaproximando a ciência da vida, o que contribuiria com a divulgação científica.

A figura do cientista continua sendo fartamente utilizada no cinema, na televisão e na internet com imagens de cientistas sendo alvo de chacota e tendo comportamentos pouco convencionais, considerados socialmente desajustados, interessados em usar a ciência para atender às suas próprias necessidades e desejos, não se preocupando em retratar problemas da nossa cotidianidade.

Esse tipo de tratamento [do cientista] reforça preconceitos e trabalha fortemente na construção do imaginário, pois, um público com pouco acesso a outras fontes de informação, tenderá a dar importância, mesmo que eles não tenham consciência disso. (SIQUEIRA, 2006, p.136).

Com o tempo, tais deformações, que expressam em conjunto uma imagem ingênua, profundamente afastada do que se supõe ser a construção do conhecimento e do trabalho científico, vão se consolidando até se tornarem um estereótipo socialmente aceito, que a própria educação científica reforça ativa ou passivamente (PÉREZ et al., 2001).

Com base nesses pressupostos, justifica-se a relevância do conhecimento elaborado nessa pesquisa não apenas por apresentar critérios para a seleção, análise e planejamento de atividades de ensino da ciência com filmes de animação, mas, principalmente, por contribuírem para a reflexão sobre as concepções de ciência veiculadas nas práticas de educação científica formal e informal.

\title{
2. PROCEDIMENTOS METODOLÓGICOS
}




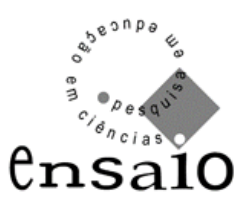

Para investigar as imagens de ciência e cientista veiculadas nos filmes de animação infantil foram selecionados todos os filmes deste gênero, encontrados em setembro de 2008 nas duas maiores vídeo locadoras do município de Blumenau - SC, que contivessem mencionadas em sua sinopse as palavras ciência, cientista, laboratório, experimento, pesquisa, pesquisador/es, investigação/lógica científica, invenção e/ou inventor/es.

Assistiu-se aos filmes selecionados, os quais foram analisados com o auxílio de um roteiro de observação (apêndice A) composto por categorias pré-estabelecidas, elaboradas com base nas leituras, principalmente das "visões deformadas de ciência e tecnologia” conjecturadas por Cachapuz et al. (2005) e com base em informações decorrentes dos filmes.

Para análise das informações organizadas nas categorias foram elaborados eixos temáticos, os quais foram abordados com excertos das observações e interpretados com base nos fundamentos teóricos.

\section{RESULTADOS E DISCUSSÃO}

Foi encontrado um $n$ amostral de nove produções cinematográficas infantis, abaixo descriminadas com os trechos que mencionam as palavras alvo desse estudo, retiradas de suas respectivas sinopses:

a) A Família do Futuro: “... responsável por invenções inteligentes $e$ surpreendentes...”

b) Stitch! - O Filme: “... alien resultado da experiência 626...” “... é responsável por 625 experimentos genéticos que estão clandestinos...”

c) Jimmy Neutron: Boy Genius: “... Jimmy Neutron é um brilhante inventor...” “... uma das suas invenções...”

d) Pinky e Cérebro: “... camundongos geneticamente modificados nos Laboratórios Acme...”

e) As Meninas Superpoderosas-Conhecendo os Beat-Alls: “... Elemento $X$ no laboratório do Professor..."

f) Steamboy: “...um épico de ficção-científica retrô que se passa...” “...onde um inventor prodígio chamado Ray Steam...” 


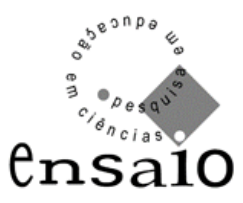

g) Mamãe Virei Um Peixe: “...descobrem o laboratório de um cientista muito engraçado..."

h) Cine Gibi - O Filme, com A Turma da Mônica: “... Franjinha - o inventor da turma..." “... ele inventa um liquidificador...”

i) Jonny Quest - 1ª Temporada: “...usou lógica científica de investigação...”

A seguir encontram-se os eixos temáticos em relação à concepção de ciência e cientista estabelecidos e interpretados com base no referencial teórico.

\subsection{Concepção de ciência}

A construção do conhecimento científico e as suas relações com: a dimensão temporal, a utilidade/aplicação do conhecimento, os procedimentos metodológicos e o êxito com a pesquisa.

A maior parte das animações estudadas (oito) acontece em tempo contemporâneo, o que se pôde observar pelo vocabulário, vestiário e assuntos discutidos. Somente no filme Steamboy o enredo ocorre no século XIX, na Inglaterra vitoriana, onde a personagem principal busca conhecimentos científicos para aperfeiçoar a aplicação da energia obtida através do vapor. Em Jimmy Neutron: Boy Genius e A Família do Futuro há algumas passagens em que aparecem "pessoas do futuro”, reforçando uma imagem de que a ciência é mais evoluída. No entanto, na maioria (sete) dos filmes não há evidência de aspectos históricos, nem coletivos, na construção do conhecimento, parecendo que os cientistas resolvem, sem pressupostos e/ou referência a outros estudos, investigar um objeto. Um exemplo disso acontece em uma das cenas de A Família do Futuro, quando uma cientista, ao conversar com o Diretor da Escola, por ocasião da feira de ciências, apresenta um adesivo de cafeína para se manter acordada e afirma com ênfase “- é invenção minha!”.

Dessa forma, as animações acabam por legitimar a ciência a partir de:

Uma concepção que defende o papel da observação e da experimentação "neutra” (não contaminadas por ideias apriorísticas), esquecendo o papel essencial das hipóteses como focalizadoras da investigação e dos corpos coerentes de conhecimentos (teorias) disponíveis, que orientam todo processo. (CACHAPUZ, 2005, p.45). 


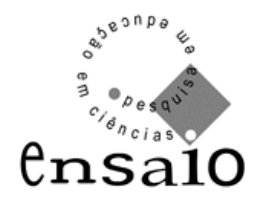

As animações em Stitch! O filme e A Família do Futuro apresentam, de forma positiva, as personagens pesquisadoras buscando informações sobre o assunto investigado em publicações específicas como periódicos ou livros, antes ou durante a realização de suas experimentações, diminuindo uma imagem de ciência a-histórica e individualista.

Em relação à aplicação/finalidade das pesquisas, nas animações A Família do Futuro, Jimmy Neutron: Boy Genius e Pinky e Cérebro a ciência é usada exclusivamente para uso próprio, na invenção de espaçonaves feitas à mão para salvar os próprios pais dos poderes dos alienígenas e a realização de experimentos para domínio do mundo, respectivamente. Esses dados permitem demonstrar a visão de que o cientista trabalha para benefício próprio, sem uma problematização do conhecimento científico e seus usos e impactos nos meios naturais - sociais culturais.

Já em Mamãe Virei um Peixe, Cine Gibi - O Filme, com a Turma da Mônica, As Meninas Superpoderosas - Conhecendo Os Beat-Alls e Jonny Quest-1 ${ }^{a}$ Temporada a ciência é vista somente como um instrumento para o bem comum. As personagens pesquisadoras realizam suas pesquisas, procurando solucionar uma problemática ou criar algo que seja de utilidade a todos, como investigar uma poção capaz de transformar pessoas em animais aquáticos, aptos a sobreviverem ao aumento do nível do mar provocado pelo aquecimento global; criar um liquidificador que engole revistas em quadrinhos e projeta suas histórias nas telas dos cinemas; conceber meninas com superpoderes para salvar o planeta, solucionar mistérios e aprisionar vilões através de lógica científica, respectivamente. Os filmes reforçam a imagem de uma ciência "salvadora da humanidade”, sem considerar os interesses sócio-políticoeconômicos envolvidos em seu desenvolvimento.

Por outro lado, Stitch! O filme e Steamboy perpassam duas finalidades do conhecimento científico produzido tanto para uso comum, como para uso próprio. Em Stich! O filme, durante a aventura, Lilo e Stitch ativam a experiência 221 que é um raio vivo projetado para absorver e controlar eletricidade. Também foi ativada a experiência 625 que tem uma superforça, mais inteligente que um supercomputador e praticamente indestrutível, feita para destruir grandes cidades. Em Steamboy, uma 


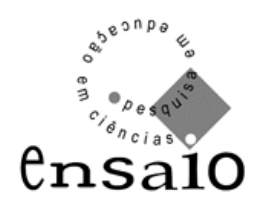

nova forma de energia obtida a partir do vapor é criada para abastecimento energético em escala mundial, mas um dos cientistas - o pai do garoto inventor Ray Steam tenta usar o invento para benefício próprio, criando armas muito potentes, capazes de uma destruição em massa.

Em sete animações analisadas os cientistas obtêm êxito em sua pesquisa, algumas vezes com outro resultado, diferente do esperado, como é o caso de Stitch! O filme e As Meninas Superpoderosas - Conhecendo Os Beat-Alls. Nessa última, o Professor - cientista consegue criar garotas a partir de uma mistura de elementos, porém as mesmas não são perfeitas como desejava, pois ocorreu um erro na fórmula. Nas produções A Família do Futuro e Pinky e Cérebro, os pesquisadores, em grande parte dos experimentos, não possuem êxito algum, culminando muitas vezes em explosões e decepções. Pode-se observar que as animações reforçam que os "erros" cometidos pelos cientistas são problemas na “exatidão" e na “objetividade” da condução do experimento, acabando por fadar o estudo.

É preciso reconhecer, pelo contrário, que este carácter "tentativo" se traduz em dúvidas sistemáticas, em redefinições, procura de novas vias, etc. que mostram o papel essencial da investigação e da criatividade, contra toda ideia de método rígido, algorítmico. (CACHAPUZ et al., 2005, p.48, grifo nosso)

A concepção de ciência como um processo isento de erros fez-se presente em Mamãe Virei um Peixe e Jonny Quest- ${ }^{a}$ Temporada, pois nesses filmes as personagens pesquisadoras sempre realizam “o método" correto para alcançar o resultado esperado, como em uma única tentativa criar uma poção antítodo para tornar seres humanos, transformados em animais aquáticos, em novamente humanos.

Essa imagem de um método rígido acaba por enfatizar a concepção de que o conhecimento científico é construído por um “método científico” único, com uma sequência de etapas definidas em que as observações e experiências desempenham fatores decisivos.

O método científico não é um procedimento lógico, algorítmico, rígido. $\mathrm{Na}$ prática, muitas vezes, o cientista procede por tentativas, vai numa direção, volta, mede novamente, abandona certas hipóteses porque não tem equipamento adequado, faz uso da intuição, dá chutes, se deprime, se entusiasma, se apega a uma teoria. Enfim, fazer ciência é uma atividade humana, com todos os defeitos e virtudes que o ser humano tem, e com muita teoria que ele tem na cabeça. Conceber o método científico como uma seqüência rigorosa de passos que o cientista segue disciplinadamente é 


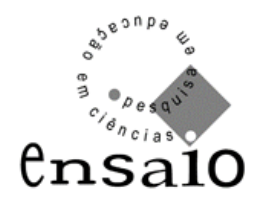

conceber de maneira errônea a atividade científica. (MOREIRA, OSTERMANN, 1993, p.114)

As imagens de uma ciência descontextualizada, individualista, ateórica, empírica, rígida e infalível evidenciadas na maioria das animações infantis examinadas também foram observadas por Siqueira (2006), em uma pesquisa feita em desenhos animados exibidos em canais comerciais abertos e/ou na TV por assinatura, em que encontrou personagens que não utilizavam a ciência em nome de um bem maior, resumindo-se o processo científico à causa própria. Além disso, dados obtidos nos estudos com alunos de ensino fundamental, através de enredos de histórias de ficção científica e entrevistas semiestruturadas sobre o trabalho de cientistas, por Reis, Rodrigues e Santos (2006), evidenciaram a percepção de que o pesquisador trabalha motivado pelo desejo de contribuição para o bem-estar da humanidade, seguido pelo reconhecimento pessoal, obtenção de conhecimento e, ainda, por ganância ou desejo de poder. De uma maneira geral, os estudantes participantes dessa investigação evidenciam concepções positivas acerca dos cientistas e da sua atividade, contudo, acreditam que a ciência e a atividade dos cientistas pode ser, simultaneamente, útil e perigosa.

Conclusões de pesquisas como estas provocam a reflexão sobre a necessidade de uma maior discussão sobre as imagens de ciência que são veiculadas socialmente (incluindo a escola), uma vez que a falta de compreensão social sobre a atividade científica pode originar a perda de prestígio, interesse e apoio público à ciência, bem como o desencorajamento de muitas crianças de prosseguirem a carreira científica. (ALBAGLI, 1996; REIS; RODRIGUES; SANTOS, 2006).

Para Kosminsky, Giordan (2002) e Siqueira (2006), no que tange à ideia de ciência e à de cientista, a pluralidade deveria ser mostrada em seus processos e em seus métodos. A mídia seria mais correta, se apresentasse o caráter dinâmico da pesquisa, a natureza da dúvida, a influência de concepções diversas do sujeito e a existência de conflitos entre diferentes linhas de pensamento sobre a ciência e aqueles que a praticam.

\subsection{Concepção de cientista}




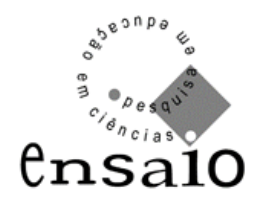

\subsubsection{Sexo, idade aproximada e estilo}

Todos os filmes apresentam o profissional cientista no sexo masculino, sendo que somente no filme A Família do Futuro, há também a passagem de uma cientista, vinda de uma universidade, que participa da feira de ciências do colégio como avaliadora e acaba analisando o invento do personagem principal - Lewis, o menino cientista.

Na maioria dos filmes (cinco), é apresentado o profissional cientista adulto. Em Jimmy Neutron: Boy Genius e Cine Gibi - O Filme, com a Turma da Mônica, a ciência é exercida somente por crianças. Já na produção A Família do Futuro, há um cientista adulto e um infantil. Somente no filme Steamboy, as pesquisas são realizadas por uma criança, um adulto e um idoso.

O estilo dos cientistas, em sua maioria, é casual (cinco). Em Mamãe Virei um Peixe, Jonny Quest-1 ${ }^{a}$ Temporada, Cine Gibi - O Filme, com a Turma da Mônica e As Meninas Superpoderosas - Conhecendo Os Beat-Alls, a ciência é exercida por pessoas uniformizadas de jaleco. Vale ressaltar que em Mamãe Virei um Peixe o cientista é um biólogo marinho, veste bermuda, anda descalço ou usa apenas meias, mas sempre com um jaleco. Também no filme A Família do Futuro, a cientista visita a escola de jaleco.

Os dados obtidos permitem constatar que o principal estereótipo transmitido nos filmes de animação infantil é de um cientista homem, adulto, trajado casualmente e, na maioria das vezes, com jaleco, mesmo quando não está trabalhando em sua pesquisa.

Da mesma forma, estudos de percepções do cientista por alunos e aquelas transmitidas em programas de canais comerciais voltados para o público infantil, constataram uma visão estereotipada do profissional cientista: sexo masculino, usando óculos e jaleco, por vezes cabeludo e despenteado (KOSMINSKY; GIORDAN, 2002; MASSARANI, 2005; REIS; RODRIGUES; SANTOS, 2006; SIQUEIRA, 2006; ZOMPERO; GARCIA; ARRUDA, 2005).

Esta visão deformada transmite uma concepção elitista da ciência, insiste-se que o trabalho científico é um domínio reservado a minorias especialmente dotadas, transmitindo assim expectativas negativas, com claras discriminações de natureza social e sexual (PÉREZ et al., 2001). Isso pode ser observado na abertura do filme 


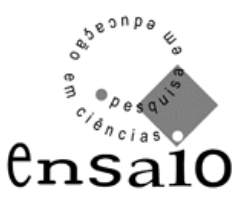

Pinky e Cérebro, ao apresentar os dois em meio às vidrarias e cálculos, a música diz “um é um gênio e o outro é um imbecil”, reforçando como gênio o ratinho que faz os cálculos e os experimentos.

Zompero, Garcia e Arruda (2005) afirmam ser importante a visão de cientista “normal como todas as pessoas", por não considerar o cientista como uma pessoa neutra, alheia à sociedade, mas pessoa comum, um trabalhador, como as demais. Isto contribui para desmistificar a ideia de ciência como atividade para poucos, possuidores de uma inteligência anormal ou de hábitos adversos a todos.

\subsubsection{Etnia, características psicológicas e convívio social}

Todas as personagens humanas (sete) possuem etnia caucasiana. Não foi constatado nenhum pesquisador afro descendente e/ou amarelo. Em Stich! O Filme, o cientista é um alien e em Pink e Cérebro, um rato de laboratório, no entanto com características psicológicas humanas. Em Stitch! O Filme, o pesquisador passa uma visão de loucura e melancolia. Já em Mamãe Virei um Peixe, o cientista é atrapalhado e também apresenta indícios de uma personalidade tipicamente insana, em Jimmy Neutron: Boy Genius é um cientista sonhador.

Em todos os filmes pesquisados, os cientistas possuem algum tipo de relacionamento social, pois convivem com pessoas, familiares ou não. Como exceção há a cientista do filme A Família do Futuro, a qual demonstra, por seu comportamento, estar tanto tempo num laboratório que perdeu as referências para se relacionar com as pessoas, indicando reações exageradas de afeição aos outros.

Em relação à forma de trabalho, em seis produções, os pesquisadores exerciam suas pesquisas solitariamente. Em Jimmy Neutron: Boy Genius, Pinky e Cérebro e Jonny Quest-1 $1^{a}$ Temporada, as personagens cientistas recebiam auxílio de outros em suas experiências, aos quais geralmente cabiam os serviços "práticos", reforçando a imagem de que o cientista é o que "melhor pensa” e que a tecnologia se reduz a um artefato da ciência.

As pesquisas de Massarani (2005); Reis, Galvão (2006); Reis, Rodrigues, Santos (2006); Zompero, Garcia e Arruda (2005) também verificaram o estereótipo 


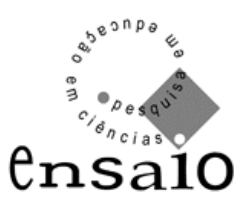

psicológico de um pesquisador louco, atormentado, perverso e extremamente inteligente.

Igualmente, o cientista solitário que trabalha e interage somente com seu mundo é uma percepção comum entre estudantes que relacionam essas características a esse profissional (KOSMINSKY; GIORDAN, 2002; REIS; RODRIGUES; SANTOS, 2006).

O agir solitário do profissional pesquisador deflagra a ausência de menção às comunidades científicas como foro de troca de ideias e de legitimação do conhecimento (KOSMINSKY; GIORDAN, 2002). Transmite-se dessa forma, uma visão individualista da ciência, cujos conhecimentos aparecem como obras de gênios isolados, ignorando-se o papel do trabalho coletivo e cooperativo, que, lamentavelmente, é uma imagem típica muito difundida no ensino das ciências (PÉREZ et al., 2001).

\subsubsection{Local de trabalho, área de investigação e instrumentos de trabalho}

O local de trabalho de todas as personagens cientistas é principalmente, ou exclusivamente, o laboratório, o qual, muitas vezes, é onde o pesquisador mora, evidenciando a forte relação que a ciência exerce na vida da personagem. Somente em Jonny Quest-1 ${ }^{a}$ Temporada, além do laboratório, o personagem trabalha em campo, utilizando-se de lógica científica para solucionar mistérios e aprisionar vilões.

Em seis animações, a área de investigação é a tecnologia, das quais, os cientistas de Jimmy Neutron: Boy Genius e Pinky e Cérebro atuam também no campo da Física e da Química. Na produção As Meninas Superpoderosas - Conhecendo Os Beat-Alls, o exercício científico tem um apelo à Química, através das vidrarias e substâncias utilizadas pelo Professor. A Biologia é o campo de atuação dos investigadores de Stitch! O filme e Mamãe Virei um Peixe. Nesse último, o cientista Professor Mac Krill é um biólogo marinho que, devido ao aquecimento global e ao consequente aumento do nível dos mares, inventa uma poção capaz de transformar seres humanos em animais aptos a viverem debaixo d'água. Pode-se observar nas animações uma visão simplista das relações entre ciência e tecnologia, muitas vezes 




passando a imagem de que a tecnologia é um produto da ciência ou aplicação do conhecimento científico.

Em todos os filmes o cientista utiliza mais do que um instrumento para pesquisar. Ferramentas de registro (seis), como diários, cadernos e computadores evidenciam a escrita na construção do conhecimento científico; substâncias químicas (cinco) e vidrarias em geral (quatro) são os principais equipamentos utilizados. Materiais alternativos, obtidos com eletrodomésticos e utensílios quebrados são comuns em produções cuja personagem cientista é uma criança e realiza as invenções em sua própria casa, como observado em A Família do Futuro, Steamboy e Cine Gibi - O Filme com a Turma da Mônica. Testes em cobaias animais não foram comuns (dois), presentes somente em Stitch! O filme e Mamãe Virei um Peixe, únicos filmes, cujos pesquisadores atuam na área biológica. Instrumentos de observação estiveram presentes nas animações Mamãe Virei um Peixe e Jonny Quest-1 ${ }^{a}$ Temporada, representados pelo uso de microscópio. Já a leitura como uma etapa da pesquisa, além das experiências, somente foi detectado em Stitch! O filme e A Família do Futur..

Em suma, os dados obtidos revelam que a atividade do cientista dá-se predominantemente na área tecnológica, exercida em laboratório, com utilização de mais de um tipo de instrumento de trabalho - sendo mais comum, ferramentas de registros, substâncias químicas e vidraria em geral.

Também Zompero, Garcia e Arruda (2005) verificaram em seu estudo que a ideia predominante do local de trabalho dos cientistas, no entender dos alunos, é o laboratório.

Em consonância, Siqueira (2006) também identificou o modelo de cientista apresentado como aquele dos laboratórios, das experiências, tubos de ensaio, pipetas e equipamentos eletrônicos. Nunca aparece um sociólogo, antropólogo, psicólogo ou cientista político. No universo do desenho e das animações, esses não parecem ser reconhecidos como profissionais das ciências, por não se enquadrarem no estereótipo de cientista divulgado pela mídia, restringindo, assim, o processo científico a poucas áreas como a Química, Biologia, Física e Tecnologia.

\section{CONSIDERAÇÕES FINAIS}




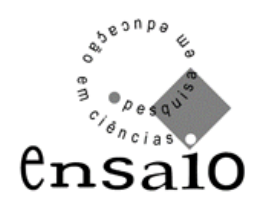

Com a pesquisa, pode-se constatar que a mídia cinematográfica infantil ainda veicula modelos de ciência e cientista com imagens afastadas do que se supõe sobre a construção de conhecimentos científicos e o trabalho de um/a pesquisador.

As animações examinadas neste trabalho, em sua pluralidade, transmitem a imagem da atividade científica com finalidade para o bem comum, como um processo de produção de conhecimento científico imediato, com poucos ou sem nenhum erro e sempre com êxito no fim.

Os dados obtidos em sua maioria permitem inferir o estereótipo do profissional cientista transmitido em filmes de animação infantil, como um homem, adulto, trajado casualmente - ou excepcionalmente uniformizado com jaleco -, de etnia caucasiana, de características psicológicas normais, que trabalha individualmente e tem como principal local de atuação o laboratório, utiliza mais de um tipo de equipamento de trabalho - sendo os mais comuns, ferramentas de registros, substâncias químicas e vidraria em geral. Assim, pode-se perceber que os filmes de animação infantil atuais proporcionam a percepção de ciência e cientista, na maioria das vezes, como sinônimo de pesquisa em laboratório.

Com os resultados da pesquisa, pode-se perceber que os filmes de animação infantil podem servir de instrumento para a educação científica, desde que sejam acompanhados por uma discussão crítica e reflexiva sobre a ciência e o profissional cientista que são veiculados.

As potencialidades educativas destes meios de comunicação e entretenimento social constituem um recurso didático a ser aproveitado pelos professores que desejam trabalhar questões relacionadas ao ensino de ciência na escola. No entanto, cabe aos professores assumirem um papel de mediação entre estes veículos de comunicação e a educação, permitindo a motivação dos alunos para as questões científicas, através da discussão dos estereótipos acerca da atividade científica, ajudando os seus alunos a assumirem-se como espectadores críticos perante o que são expostos.

Sugere-se que, na opção de adotar animações cinematográficas infantis para o ensino de ciência, sejam utilizados critérios para análise e seleção destes filmes. Em Apêndice A, segue uma sugestão de roteiro de observação dos filmes de animação infantil para os professores. 


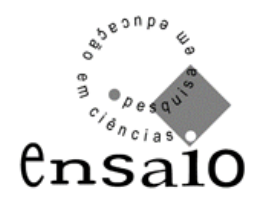

\section{REFERÊNCIAS BIBLIOGRÁFICAS}

A FAMÍLIA DO FUTURO. Produção de Steve Anderson. EUA: Disney, 2007. DVD.

ALBAGLI, S. Divulgação científica: informação científica para a cidadania? Revista Ciência da Informação, Brasília, v.25, n.3, p.396-404, 1996.

ANGOTTI, J. A. P.; AUTH, M. A. Ciência e tecnologia: implicações sociais e o papel da educação. Revista Ciência \& Educação, Bauru, v.7, n.1, p.15-27, 2001.

AS MENINAS SUPERPODEROSAS - CONHECENDO OS BEAT-ALLS. Produção de Robert Renzetti. EUA: Warner, 2001. DVD.

BRASIL. Secretaria de Educação Fundamental. Parâmetros Curriculares Nacionais: Ciências Naturais. Brasília: MEC/SEF, 1998.

CACHAPUZ, A. et al. (Orgs.). A necessária renovação do ensino das Ciências. São Paulo: Cortez, 2005.

DELIZOICOV, D.; ANGOTTI, J. A.; PERNAMBUCO, M. M.. Ensino de Ciências: fundamentos e métodos. São Paulo: Cortez, 2002.

FRANCISCO, I. H. Repensando o Brincar e a Afetividade na Educação Infantil. 2006. Monografia (Conclusão de Curso) - Pedagogia, Universidade Estadual de Campinas. 2006.

JIMMY NEUTRON: BOY GENIUS. Produção de John A. Davis, Albie Hecht e Steve Oedekerk: EUA. Paramount Pictures / UIP, 2001. DVD.

JONNY QUEST - $1^{\text {a }}$ TEMPORADA. Produção de William Hanna e Joseph Barbera. EUA. Warner, 2004. DVD.

KOSMINSKY, L.; GIORDAN, M. Visões de Ciências e Sobre Cientistas entre Estudantes de Ensino Médio. Revista Química Nova na Escola, São Paulo, n.15, p.11-18, 2002.

MAMÃE VIREI UM PEIXE. Produção de Russell Boland, Eberhard Junkersdorf e Anders Mastrup. Dinamarca. Buena Vista International / Paris Filmes, 2000. DVD.

MASSARANI, L. A divulgação científica e o público infantil. In: MASSARANI, L. (Org.). O pequeno cientista amador: a divulgação científica e o público infantil. Rio de Janeiro: Vieira \& Lent: UFRJ, Casa da Ciência: FIOCRUZ, 2005. p.7-8. 


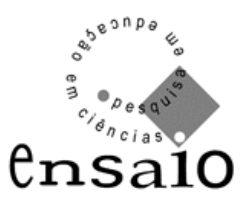

MOREIRA, M. A.; OSTERMANN, F. Sobre o Ensino do Método Científico. Caderno Catarinense de Ensino de Física, Florianópolis, v.10, n.2, p.108-117, 1993.

NUNES, C. Ciência e TV: a união possível e desejável. Revista Ciência e Cultura, Campinas, v.58, n.4, p.10-11, 2006.

OLIVEIRA, B. J. Cinema e imaginário científico. Revista História, Ciências, Saúde, Rio de Janeiro, v.13, p.133-50, 2006.

PÉREZ, D. G. et al. Para uma imagem não deformada do trabalho científico. Ciência \& Educação, Bauru, v.7, n.2, p.125-153, 2001.

PINKY E CÉREBRO. Produção de Steven Spielberg. EUA: Warner, 2006. DVD.

REIS, P.; GALVÃO, C. O diagnóstico de concepções sobre os cientistas através da análise e discussão de histórias de ficção científica redigidas pelos alunos. Revista Electrónica de Enseñanza de las Ciências, Ourense, v.5, n.2, p.213-234, 2006.

REIS, P.; RODRIGUES, S. E.; SANTOS, F. Concepções sobre os cientistas em alunos do $1^{\circ}$ Ciclo do Ensino Básico: "Poções, máquinas, monstros, invenções e outras coisas malucas”. Revista Electrónica de Enseñanza de las Ciências, Ourense, v.5, n.1, p.51-74, 2006.

SILVA, L. P. et al. A Influência do Conhecimento Sistematizado no Livro Didático nas Representações Sociais de Ciências. In: ENCONTRO NACIONAL DE PESQUISADORES EM EDUCAÇÃO EM CIÊNCIAS, 5, 2005, Bauru. Anais... Bauru, 2005. 1 CD-ROM.

SIQUEIRA, D. C. O. Superpoderosos, submissos: os cientistas na animação televisiva. In: MASSARANI, L. (Org.). O pequeno cientista amador: a divulgação científica e o público infantil. Rio de Janeiro: Vieira \& Lent: UFRJ, Casa da Ciência: FIOCRUZ, 2005. p.23-32.

O cientista na animação televisiva: discurso, poder e representações sociais. Revista Em Questão, Porto Alegre, v.12, n.1, p.131-148, 2006.

STEAMBOY. Produção de Katsuhiro Ôtomo. Japão: Sony, 2004. DVD.

STITCH! - O FILME. Produção de Robert Gannaway. EUA: Buena Vista, 2003. DVD.

TOMIO, D. De corpo praticante a corpo aprendente: o professor de Ciências nos seus espaços de aprender. Itajaí: Univali, 2002. 


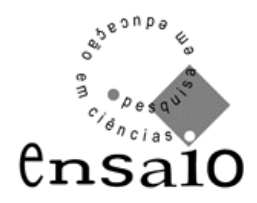

ZOMPERO, A. F.; GARCIA, M. F. L.; ARRUDA, S. M. Concepções de ciência e cientista em alunos do ensino fundamental. In: ENCONTRO NACIONAL DE PESQUISADORES EM EDUCAÇÃO EMDE CIÊNCIAS, 5, 2005, Bauru. Anais... Bauru, 2005. 1 CD-ROM.

\section{APÊNDICE A: Roteiro de avaliação para caracterização da concepção de ciência e de cientista veiculadas em filmes de animação infantil.}

\begin{tabular}{|c|c|c|}
\hline \multicolumn{3}{|l|}{ Filme: } \\
\hline \multicolumn{3}{|l|}{ CONCEPÇÃO DE CIÊNCIA } \\
\hline \multicolumn{2}{|l|}{ Critérios } & Observações \\
\hline $\begin{array}{l}\text { Em que dimensão temporal acontece o } \\
\text { filme }\end{array}$ & $\begin{array}{l}\text { ( ) Passado } \\
\text { ( ) Presente } \\
\text { ( ) Futuro }\end{array}$ & \\
\hline Utilidade/aplicação da pesquisa & $\begin{array}{l}\text { ( ) Para próprio uso } \\
\text { ( ) Para uso social }\end{array}$ & \\
\hline Êxito com a pesquisa & $\begin{array}{l}\text { ( ) Sim } \\
\text { ( ) Não }\end{array}$ & \\
\hline Construção do conhecimento científico & $\begin{array}{l}\text { ( ) apresenta aspectos históricos na } \\
\text { construção do conhecimento } \\
\text { ( ) faz referência a outros estudos } \\
\text { ( ) apresenta coletividade da construção } \\
\text { do conhecimento científico } \\
\text { ( ) revela idéia de processo } \\
\text { ( ) caracteriza o erro como "uma } \\
\text { tentativa" } \\
\text { ( ) não reduz os procedimentos da } \\
\text { pesquisa ao "empírico" }\end{array}$ & \\
\hline \multicolumn{3}{|l|}{ CONCEPÇ̃̃O DE CIENTISTA } \\
\hline \multicolumn{2}{|l|}{ Critérios } & Observações \\
\hline Sexo: & $\begin{array}{l}\text { ( ) Masculino } \\
\text { ( ) Feminino }\end{array}$ & \\
\hline Idade aproximada: & $\begin{array}{l}\text { ( ) Criança } \\
\text { ( ) Jovem } \\
\text { ( ) Adulto } \\
\text { ( ) Idoso }\end{array}$ & \\
\hline Estilo de roupa & $\begin{array}{l}\text { ( ) Casual } \\
\text { ( ) Social } \\
\text { ( ) Uniformizado }\end{array}$ & \\
\hline Características psicológicas & $\begin{array}{l}\text { ( ) Louco } \\
\text { ( ) Sonhador } \\
\text { ( ) Carente } \\
\text { ( ) Melancólico } \\
\text { ( ) Normal }\end{array}$ & \\
\hline Etnia & $\begin{array}{l}\text { ( ) Caucasiano } \\
\text { ( ) Afro descendente } \\
\text { ( ) Amarelo }\end{array}$ & \\
\hline Convívio social & $\begin{array}{l}\text { ( ) Trabalha em equipe } \\
\text { ( ) Trabalha individualmente } \\
\text { ( ) Vida social } \quad \text { ( ) Vive isolado }\end{array}$ & \\
\hline Local de trabalho & $\begin{array}{l}\text { ( ) Laboratório } \\
\text { ( ) Campo } \\
\text { ( ) Biblioteca / Arquivo... }\end{array}$ & \\
\hline Área de investigação & $\begin{array}{ll}\text { ( ) Física } & \text { ( ) História } \\
\text { ( ) Química } & \text { ( ) Social }\end{array}$ & \\
\hline
\end{tabular}




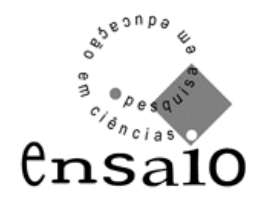

\begin{tabular}{|l|l|l|}
\hline & $\begin{array}{l}\text { ( ) Biologia ( ) Tecnologia } \\
\text { ( ) Matemática ( ) Outras }\end{array}$ & \\
\hline Instrumentos de trabalho & $\begin{array}{l}\text { ( ) De observação } \\
\text { ( ) Vidraria em geral } \\
\text { ( ) Substâncias químicas } \\
\text { ( ) Cobaias } \\
\text { ( ) De registro } \\
\text { ( ) De leitura } \\
\text { ( ) Alternativos }\end{array}$ & \\
\hline \multicolumn{2}{|l}{} \\
\hline
\end{tabular}

Data de recebimento: 06/05/09

Data de aprovação: 28/08/09

Data de versão final: 07/09/09 